\title{
Aortic diseases
}

In 1956, DeBakey and colleagues published the first four cases of thoracoabdominal aorta involving the celiac, superior mesenteric, and renal arteries treated by resection and homograft replacement (1). Sixty-one years later, we need to take into account the great progress over the surgical techniques, perioperative and intraoperative care, imaging techniques and endovascular treatment to begin to understand why an update on aortic diseases is needed from time to time.

In this issue, created for the Fournal of Thoracic Disease, we report, talk and discuss on the need to unify criteria for image techniques, the last guidelines on aortic diseases, the need of new predictive models for mortality after aortic surgery, surgical and image techniques challenges, reoperations, the role of medical treatment on these diseases, we show sparing aortic root repairs. We even talk about the problem of health care cost control in Spain and other European countries where there is public and free Health System or the birth of the Star Chamber, an ingenious idea to prevent surgeons from running away from high-risk interventions (2).

I would like to close thanking the Editor in Chief, Prof. Dr. Nanshan Zhong, and the other Associate Editors of the Fournal of Thoracic Disease, the opportunity you gave me to organize this special issue. Amy Liu, Science Editor has played a key role in the creation of this issue. Without her extraordinarily effective work, it would have been impossible. Finally, I would like to thank the researchers and colleagues who collaborate and share their experience in this issue.

I sincerely hope that this special issue will serve as a valuable resource and a guide on the latest developments and techniques in the management of patients with this serious but treatable disease.

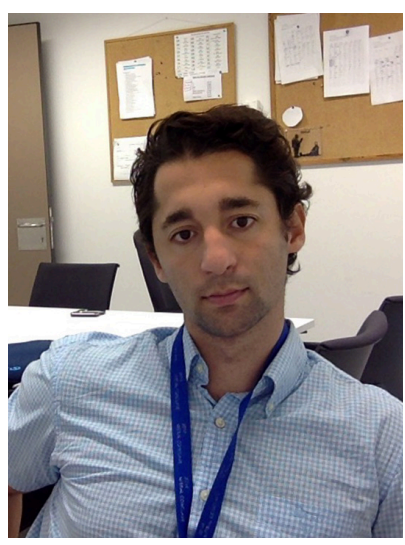

Daniel Hernandez-Vaquero
Daniel Hernandez-Vaquero, MD, PhD Heart Area, Central University Hospital of Asturias, Oviedo, Spain. (Email: dhvaquero@gmail.com) doi: $10.21037 /$ jtd.2017.04.68

Conflicts of Interest: The author has no conflicts of interest to declare. View this article at: http://dx.doi.org/10.21037/jtd.2017.04.68

\section{References}

1. DeBakey ME, Creech O Jr, Morris GC Jr. Aneurysm of thoracoabdominal aorta involving the celiac, superior mesenteric, and renal arteries; report of four cases treated by resection and homograft replacement. Ann Surg 1956;144:549-73.

2. Nashef S. The Naked Surgeon: The Power and Peril of Transparency in Medicine. Brunswick, Victoria, Australia: Scribe Publications, 2015.

Cite this article as: Hernandez-Vaquero D. Aortic diseases. J Thorac Dis 2017;9(Suppl 6):S425. doi: 10.21037/jtd.2017.04.68 